\title{
Is YouTube Advertising Effective: Context of Travel Industry?
}

\author{
By Elmira Djafarova ${ }^{*}$ \& Kristina Kramer ${ }^{ \pm}$
}

\begin{abstract}
The tourism industry was identified as one of the industries with the highest expenditures on online advertising and experienced major changes through the rise of social media. The purpose of this study is to evaluate the effectiveness of YouTube advertising in the context of the tourism. 15 faceto-face interviews were conducted to collect primary data. These research findings suggest to use YouTube advertising when the objective is to create brand awareness or remind customers of a product. YouTube advertising is less suitable for advertising objectives focusing on persuading tourism customers to purchase.
\end{abstract}

Keywords: advertising effectiveness, tourism, Trivago, YouTube

\section{Introduction}

The opportunities offered by online advertising are used by multiple industries but to different extents. After finance and retail, the travel and tourism industry is the sector with the highest expenditures on online advertising (Faith 2014). Especially meta search engines such as Trivago and Kayak as well as hotel chains like Marriott are heavily investing into online advertising (Wordstream 2011). Social media is one of the "two mega trends" (Xiang and Gretzel 2010) influencing the tourism system and has major impacts on the consumer decision-making process. Especially within the stage of information search, its influence is considered as particularly strong (Xiang and Gretzel 2010). Thus, social media channels are an essential part of many touristic organisations' advertising strategy. However, major companies such as Trivago are facing low returns on advertising spend. In the first nine months of 2016, Trivago spent $\$ 562.1$ million on advertising, however, its return on advertising spend is with $116.1 \%$ relatively low and contributed to the company's net loss of $\$ 53$ million in the first nine months of 2016 (Jhons, 2016). For the organisation and the industry as a whole, YouTube is a major advertising channel as consumers are increasingly searching for travel-related content on YouTube (Crowel et al. 2014). As previous research did not assess the effectiveness of YouTube for specific products or industries, this study analyses how effective YouTube advertising is with the example of Trivago and identifies wider implications for the tourism industry.

Having a large user base of over one billion active users (YouTube 2017) and offering a wide range of advertising formats, YouTube is considered as highly

*Principal Lecturer, Northumbria University, UK.

${ }^{ \pm}$Former Research Student, Newcastle Business School, Northumbria University, UK. 
effective in terms of engaging existing audiences, reaching new audiences (Rohrs 2014), building brand awareness and promoting products via advertising (Miller 2011). A major form of advertising on YouTube are so-called 'in-stream video advertisements': audio-visual video advertisements placed within YouTube videos which are considered as particularly effective due to their high degree of attention demanded.

YouTube seems promising and is strongly promoted by Google, it is also criticised for providing mostly lower value user generated content (UGC) and not being able to provide a top-quality entertainment context for advertisements as traditional channels such as television do (Shields 2016). Social networking sites such as Facebook, Instagram, Pinterest, Twitter and Snapchat provide increasingly competing opportunities for online video advertisements (LePage 2016). According to eMarketer (2016a), YouTube will be able to maintain its market share throughout 2017 but will face a downward trend due to this competition. Lastly, online advertising is also often perceived as irritating (Ibrahim 2013) and can lead to negative views of the advertised brand (Smith 2012).

\section{Literature Review}

\section{How Tourism Uses Social Media for Advertising}

The rise of social media has led to fundamental changes in business-tobusiness, business-to-consumer and consumer-to-consumer communications (Leung et al. 2013). Particularly the tourism industry has been affected by this development and experienced major impacts of social media on the consumer decision-making process, promotion and interaction with consumers (Hudson and Thal 2013, Zeng and Gerritsen 2014). Xiang and Gretzel (2010) identified the developments within social media and search engines as the "two mega trends" ( $p$. 179) that significantly influence the tourism system. Although social media is considered to affect all stages of the tourist's decision-making process (Leung et al. 2013), its influence is considered as particularly strong within the stage of information search (Xiang and Gretzel 2010). According to Leung et al. (2013), significant amounts of travel information are collected and reviewed by travellers on social media early in the decision-making process as tourism-related products and services are highly priced, differentiated and, thus, require high involvement. One of the most important information sources is reviews and experiences shared by other consumers, which are referred to as eWOM and UGC in the context of social media (Leung et al. 2013). EWOM is considered as highly trustworthy by consumers due to the lack of commercial self-interest of the publisher and tends to be more influential than commercial sources (Leung et al. 2013). Hence, multiple studies have researched the impact of UGC or eWOM on early stages of the consumer decision-making process within the tourism industry (e.g., Ayeh et al. 2013, Cox et al. 2009, Manap and Adzharuin, 2013). 
In terms of advertising, Fotis et al. (2012) state that leveraging social media to market tourism products has shown to be an excellent strategy. Leung et al. (2013) outline the significance of blogs as a promotional tool within the tourism industry due to the opportunity of creating lively and credible content and connecting organisations with their customers. YouTube is also considered as an important promotional tool for tourism organisations as users can be provided with audiovisual content of destinations and accommodations (Reino and Hay 2016). Currently, there is only one study that examines the use of YouTube in tourism. However, it focuses on the role of visual UGC on YouTube for creating destination images (Reino and Hay 2016). Within the study, 320 tourism videos uploaded to YouTube by individuals and destination marketing offices have been analysed. Major findings included that YouTube is a strong tool to shape a destination's image (Reino and Hay 2016). However, the various stakeholders involved in tourism are still struggling to use its full potential (Reino and Hay 2016). Moreover, Reino and Hay (2016) state that YouTube is a useful tool for the accommodation sector to publish promotional videos. Nevertheless, no research has been conducted yet to evaluate the effectiveness of advertising on YouTube within the tourism industry. Moreover, previous research regarding advertising effectiveness within tourism focused mainly on destinations (e.g., Pratt et al. 2010, Shani et al. 2010).

YouTube offers organisations a wide range of advertising opportunities, segmented into in-stream video and in-video advertisements (Dehghani et al. 2016). In-stream advertisements are integrated into the video and can be further distinguished by their position within the video: Pre-roll advertisements are shown before the video, mid-roll advertisements during the video and post-roll advertisements are placed at the end of the video ( $\mathrm{Li}$ and Lo 2015). The purpose of in-stream advertisements is to attract attention by interrupting the video a user would like to watch. Thus, the main characteristic of in-stream advertisements is the difficulty to ignore them ( $\mathrm{Li}$ and Lo 2015). However, advertisers can also choose whether the advertisement can be skipped to reduce the degree of intrusiveness (YouTube 2012). In-video advertisements are less intrusive, mostly static overlay advertisements that appear on the bottom of the YouTube video player. If desired, the user can minimise or close these advertisements (Dehghani et al. 2016).

Advertisements on YouTube can be targeted by geographic and demographic criteria or via topics (YouTube 2012). Due to the platform's user demographics, YouTube advertising is considered as particular effective among younger target audiences. The majority of YouTube users is between 25 and 34 years old, followed by the age groups from 35 to 44 and 18 to 24 years (Blattberg 2015). Regarding their educational background, YouTube users are more likely to have a college degree or a comparable qualification than the general population (Nielsen 2016). In terms of geographic origin, the largest share of YouTube users is based in the United States of America, followed by Brazil, Russia, Japan, India, the United Kingdom, Germany, France, Mexico and Turkey (Statista 2016). Males and females are equally active on YouTube (Nielsen 2016). 


\section{Evaluating Advertising Effectiveness}

Traditional measures of advertising effectiveness remain relevant in the context of interactive advertisements as the consumers' response is similar to traditional media (Pavlou and Stewart 2000). However, Pavlou and Stewart (2000) also emphasise the need of incorporating the consumers' interaction with an advertisement when assessing the effectiveness of online advertising instead of merely assessing their response to it.

Considering this new paradigm, Martin-Santana and Beerli-Palacio (2012) distinguish between three types of measuring advertising effectiveness. According to Martin-Santana and Beerli-Palacio (2012), the most commonly used cognitive measurements are memory-based techniques such as aided and unaided brand recall and recognition. Affective measurements include aspects such as the liking and attitude towards an advertisement and the advertised brand (Martin-Santana and Beerli-Palacio 2012). Within the advertising response model, Metha (1994) identified a positive relationship between the processing of an advertisement and the development of an attitude towards the advertised brand, which then influences the purchase interest and intention. This model is complemented by Hwang, Yoon and Park (2011) who found that the processing of an online advertisement influences the attitude towards the website, the advertised brand and the purchase intention (Figure 1).

Figure 1. Research Model (Adapted from Hwang et al. 2011, p. 900)

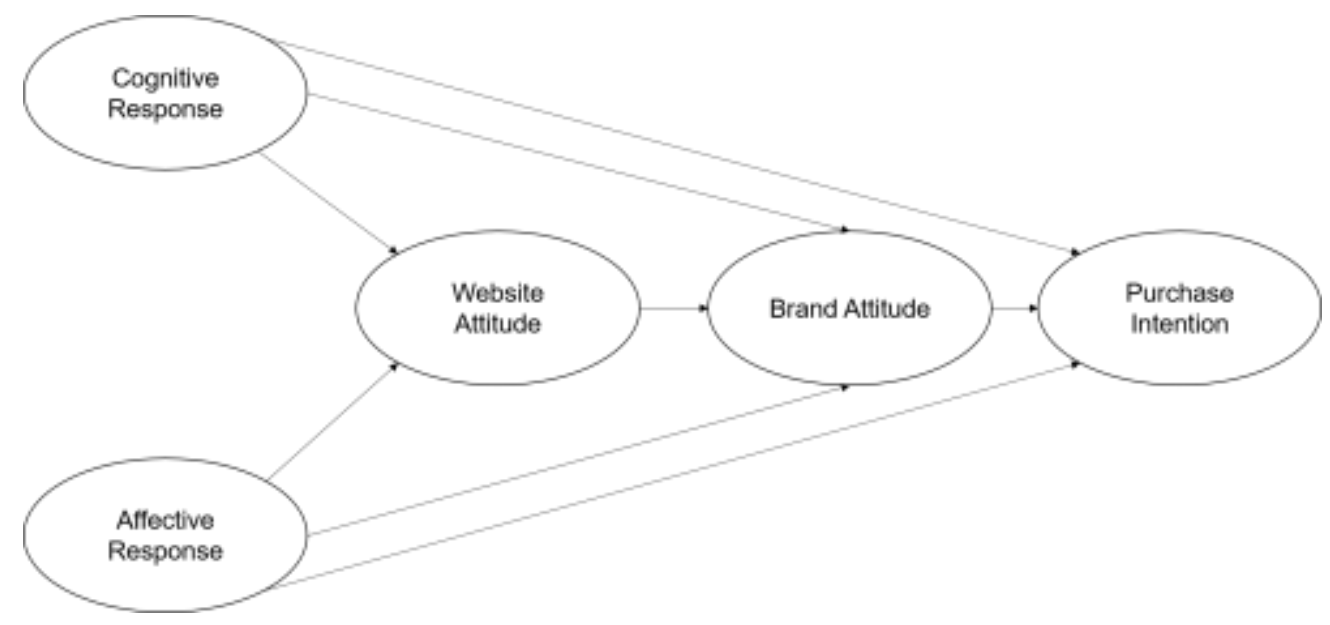

The last set of metrics is represented by conative measurements, which emerged through the interactivity of online advertising. Martin-Santana and BeerliPalacio (2012) state that the click-through rate (CTR) is the "most widely-used conative measurement of online effectiveness" (p. 423). Click-through occur when users click on an advertisement and are transferred to the advertiser's website (Chatterjee 2001). The CTR describes the ratio between the number of users who have seen an advertisement and the number of those who have clicked it (Rosenkrans 2009). It is widely discussed whether CTR is an effective indicator for 
measuring online advertising effectiveness. Although it measures a direct response to the advertisement and is easily tracked, Chandon et al. (2003) argue that CTR measures only short-term effects and neglects the aspect that the advertisement can also have an impact on the user when it is not clicked on.

An important aspect of an online video advertisement's format is its length. YouTube offers in-stream advertisements at lengths of 15, 30 and 60 seconds or longer (YouTube 2012). Li and Lo (2015) found that the longer an online video advertisement is, the higher is the likelihood of the advertised brand being recognised. Furthermore, an online video advertisement's position affects its effectiveness. Krishnan and Sitaraman (2013) found that mid-roll advertisements have higher completion rates than pre- and post-roll advertisements as viewers are less engaged in the beginning and at the end of the video. However, mid-roll advertisements are also perceived as most intrusive as they interrupt the viewer whilst watching the video ( $\mathrm{Li}$ and Lo 2015).

Moreover, Belanche et al. (2017) and Li and Lo (2015) analysed the effect of context congruency. Context congruence refers to the degree of similarity between the video and the advertisement content (Belanche et al. 2017). According to Weber's law, stimuli that differ from other stimuli are more likely to be noticed by consumers (Solomon 2013). It is assumed that through the more differing stimuli when using incongruent advertisements, more internal processing is activated and thus incongruent advertisements are remembered better (Feltham and Arnold 1994). In contrast, other authors argue that advertising messages within congruent contexts are more effective as the information is processed more intensely and positively and thus the congruency favourably influences the evaluation of the advertisement and attitude towards the brand (Belanche et al. 2017).

\section{Research Gap and Framework}

The tourism industry has been identified as one of the industries, which experienced the most significant changes through the emergence of social media (Xiang and Gretzel 2010). Moreover, YouTube is considered as a tool with a high potential for promotional efforts within tourism as accommodation providers and destination management offices can offer audio-visual content regarding their products and services and consumers are increasingly searching for travel-related information on YouTube (Crowel et al. 2014, Reino and Hay 2016). Therefore, this study will assess the effectiveness of YouTube advertising within the tourism industry.

Previous research of advertising effectiveness within the tourism industry focused mainly on destinations. Besides destinations, multiple other service providers such as accommodation providers, carriers, tour operators, travel agencies and meta search engines are part of the tourism industry. However, none of these stakeholders have been subject to research of online advertising effectiveness yet. This is especially surprising since hotel chains and meta search engines such as Trivago and Kayak are among the organisations with the highest online advertising expenditures and make significant use of advertising opportunities on social media 
with YouTube being a substantial part of their advertising strategy (eMarketer 2016a, Wordstream 2011). However, as already mentioned within the introduction, especially Trivago is facing low returns on advertising spend (Jhonsa 2016). Therefore, the focus of this study will be to assess the effectiveness of YouTube advertising within the tourism industry on the example of the meta search engine Trivago.

The literature review has shown that due to the information-intense nature of tourism-related products, social media has a significant role within the search stage of the consumer decision-making process (Xiang and Gretzel 2010). Travellers use social media in particular to collect information about destinations, accommodations and experiences of other consumers (Crowel et al. 2014). Hence, it has to be examined whether advertising by touristic organisations on social media is only effective, when users are already interacting with travel-related information. Therefore, also the effect of context congruence between the video and the advertisement will be assessed within this work. Figure 2 shows the framework that will be applied to analyse the effectiveness of YouTube advertising in this research.

Figure 2. Research Framework

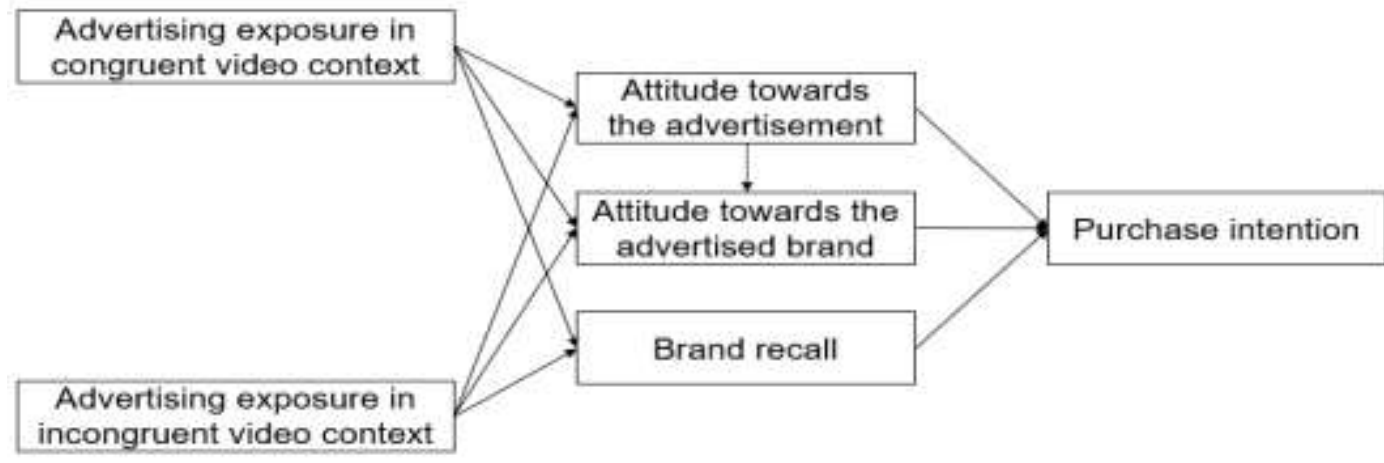

\section{Methodology}

For this research, semi-structured interviews were selected as they enable the researcher to gain in-depth insights and understanding of attitudes, opinions, processes, experiences and behaviours (Rowley 2012). The employed questions were of open, specific and probing nature. Thus, interviewees were encouraged to provide extensive answers and responses of greater significance could be explored further (Cameron and Price 2009).

The interviewee selection followed a purposive, homogenous sampling approach. Employing this approach, participants were selected based on the researcher's judgement on the participants' capacity to contribute to the research (Quinlan 2011). As a homogenous approach was chosen, all members of the sample were similar (Saunders et al. 2016). This similarity was based on several criteria. As the research was conducted in Germany, all participants were German nationals. Moreover, all participants were aged between 18 and 35 years as the majority of YouTube users is between 25 and 34 years old, followed by the age 
groups from 35 to 44 and 18 to 24 years (Blattberg 2015). Furthermore, interviewees needed to fulfil the criteria of having travelled at least once for touristic purposes in the past year and being regular internet users who are familiar with the platform YouTube. Lastly, the majority of interviewees had an academic background. The researcher knew all interviewees to different degrees on a personal level before the research. After 15 interviews, a saturation was identified and no new findings emerged. Thus, 15 interviews have been considered as appropriate for this research. Table 1 contains basic information regarding each interviewee.

As identified within the literature review, males and females are equally active on YouTube. Therefore, an equal gender split was approached when selecting the respondents. Moreover, all interviewees are active travellers. 12 respondents travel more than twice per year for touristic purposes.

\section{Selection of YouTube Videos and Advertisement}

At the beginning of the interview, participants were shown a YouTube video including a Trivago advertisement to assess the immediate effect of YouTube advertising on aspects such as brand recall and purchase intention within the interview. To investigate the effect of context congruence, interviewees were split into two groups out of which one watched a video out of context with the advertisement. The second group watched a video not in context with the advertisement. The integrated advertisement was the same within both groups. Table 2 provides an overview of the properties of the selected videos and the advertisement.

Selecting the videos, the aim was to find content that the participants would also watch if they were browsing independently on YouTube. Hence, it needed to be ensured that the content of the videos is not too specific but still engaging enough to create common interest. As Hamburg is Germany's third most visited city (DRV, 2017), it is likely that each interviewee has already visited the city or plans to travel there. Thus, a common interest was ensured. The second video was chosen as the tricks presented are universally applicable and, thus, a common interest in the video could be assumed. As previous research has shown that extreme stimuli within videos and advertisements irritate users (Belanche et al. 2017), videos with loud music and extreme visual effects were avoided. Moreover, videos branded by other touristic organisations were not chosen to prevent confusion when participants were asked to recall the brand advertised in the video. To create a natural environment and make the participants feel comfortable, the selected material was in German. As the video length affects advertising acceptance (Krishnan and Sitaraman 2013), both videos needed to be of the same length to ensure comparability. To identify two suitable videos, a total of 80 videos on YouTube was reviewed. 
Table 1. Interviewee Profiles

\begin{tabular}{|c|c|c|c|c|c|c|}
\hline Interviewee & Gender & Age & Educational background & Usage of YouTube & $\begin{array}{c}\text { Number of touristic trips in } \\
\text { past year }\end{array}$ & Booking behaviour \\
\hline P01 & Female & 23 & Bachelor's degree & Several times per month & More than two & Travel agency and online \\
\hline $\mathrm{P} 02$ & Female & 20 & German A levels & Daily & Two & Online \\
\hline $\mathrm{P} 03$ & Female & 24 & Bachelor's degree & Several times per week & More than two & Usually online \\
\hline P04 & Male & 24 & Secondary school certificate & Daily & More than two & Online \\
\hline $\mathrm{P} 05$ & Male & 27 & Master's degree & Daily & More than two & Online \\
\hline P06 & Male & 23 & Bachelor's degree & Daily & One & Travel agency and online \\
\hline $\mathrm{P} 07$ & Male & 25 & Bachelor's degree & Several times per week & More than two & Usually online \\
\hline P08 & Female & 23 & Bachelor's degree & Several times per month & More than two & Online \\
\hline P09 & Female & 25 & Bachelor's degree & Several times per week & More than two & Online \\
\hline P10 & Female & 25 & Bachelor's degree & Daily & More than two & Online \\
\hline $\mathrm{P} 11$ & Female & 23 & Bachelor's degree & Several times per week & More than two & Travel agency and online \\
\hline P12 & Male & 35 & Bachelor's degree & Daily & More than two & Online \\
\hline $\mathrm{P} 13$ & Female & 24 & Bachelor's degree & Several times per week & More than two & Travel agency and online \\
\hline P14 & Male & 23 & Bachelor's degree & Daily & More than two & Online \\
\hline P15 & Male & 18 & Secondary school certificate & Daily & One & Online \\
\hline
\end{tabular}

Table 2. Overview of Advertisement and Videos Shown to Participants

\begin{tabular}{|c|c|c|c|c|}
\hline & Title & Length & Description of content & Accessible via \\
\hline Advertisement & $\begin{array}{l}\text { Find your ideal hotel } \\
\text { for the best rate - } \\
\text { Trivago }\end{array}$ & $\begin{array}{c}15 \\
\text { seconds }\end{array}$ & $\begin{array}{l}\text { A visible narrator demonstrates the functionalities and advantages of using Trivago to } \\
\text { book an accommodation. The Trivago logo is present throughout the entire spot in the } \\
\text { right bottom corner. At the end of the advertisement, the logo is shown in a large } \\
\text { format and Trivago's website address is given. }\end{array}$ & https://bit.ly/2rX3YBI \\
\hline Video 1 & $\begin{array}{c}\text { Declaration of love to } \\
\text { Hamburg }\end{array}$ & $2: 20$ minutes & $\begin{array}{l}\text { The video presents the major sights of the German city Hamburg. The video engages } \\
\text { the viewer through the usage of an appealing imagery, slowly building up background } \\
\text { music and a vivid narration. }\end{array}$ & https://bit.ly/2SbHK9K \\
\hline Video 2 & $\begin{array}{l}10 \text { brilliant tricks that } \\
\text { help you along }\end{array}$ & $2: 20$ minutes & $\begin{array}{l}\text { Being completely unrelated to tourism and travel, the video presents ten so-called life } \\
\text { hacks, simple tips and tricks easing the daily life. The viewer is engaged through the } \\
\text { humorous narration and by learning about the handy tricks presented. }\end{array}$ & https://bit.ly/38Vv8JG \\
\hline
\end{tabular}




\section{Findings and Discussion}

\section{Attitude towards the Tourism Advertised Brand}

All respondents knew Trivago before the interview, in particular through television and YouTube advertising. Being asked about their opinion on Trivago, the majority of respondents stated that they have a neutral opinion on the brand as they have never booked a hotel via Trivago. P05, P13 (congruent group), P04, P08 and P12 (incongruent group) felt positive about Trivago as they consider it a useful and handy service to compare prices.

Furthermore, the interviewees were asked whether watching the advertisement changed anything about their opinion on Trivago to identify whether there is a relationship between the attitude towards the advertisement and the attitude towards the brand. Within the congruent group, this was negated by all respondents. Except for P13, who felt more positive about the brand after having seen the advertisement. Within the answers of five respondents, no relationship between the attitude towards the advertisement and advertised brand could be identified. However, among two respondents it was observed that the negative perception of the advertisement affected the attitude towards the brand and also the purchase intention negatively. P02 and P11 stated that they will not book a hotel via Trivago as they felt too disturbed and not appealed by the advertisement. These answers represented a contradiction to P02's and P11's previous statement that the advertisement did not change anything about their opinion of the brand. This partially supports Truong and Simmons (2010) who found that negatively perceived online advertisement can lead to a negative view of the advertised brand and that there is a relationship between the processing of the advertisement and the attitude towards the brand as identified by Metha (1994) and Hwang et al. (2011).

Within the incongruent group, all respondents besides P08 and P12 stated that watching the advertisement did not change their opinion on Trivago in a positive or negative way. Only P08 and P12 stated that they feel more likely to now consider Trivago through the constant repetition of the advertisement and as the advantages were well explained within the advertisement.

Being asked how the brands employing online advertising are perceived, the majority of respondents from both groups answered that they usually cannot remember, do not notice or just ignore the advertisements and thus the advertising brand. Because of the lack of conscious advertising processing due to these avoidance behaviours, no attitude towards the advertising brand is developed.

\section{Factors Influencing the Effectiveness of YouTube Advertising in Tourism}

The effect of the advertisement on the respondents' purchase intention was explored. Within the congruent group, P02, P07, P10 and P11 negated that they will book a hotel via Trivago in the future. Whereas for P02 and P11 the reason was the high degree of annoyance caused by the advertisement, P07 and P10 argued that they are also not more likely to book via Trivago as they do not depend 
on a certain brand or website and have already booking patterns which they will not change due to advertisements. In contrast, P03 and P05 stated that they might consider Trivago if it is the cheapest option but acknowledged that the choice of the booking platform would only depend on the price and not be a consequence of the exposure to the advertisement. However, P05 confirmed that due to the continuous exposure to the brand through advertising, the familiarity and thus also the likelihood to check the website increases.

Within the incongruent group, P08 and P12 confirmed that they are more likely to book via Trivago in the future. The remaining interviewees declared that they are not more likely to book via Trivago for various reasons. P01, P14 and P15 shared the opinion that the advertisement has no influence on them. P04, P06 and P09 have already different ways to book their hotels via platforms such as booking.com or directly on the website of the hotel.

In line with the findings regarding the attitude towards the brand, the advertisement failed to influence the purchase intention positively amongst individuals who did not already have a positive attitude towards the brand. However, it has to be acknowledged that there might be delayed effects of the advertisement and although they are currently denying it, interviewees will book via the website in the future due to the exposure to the advertisement.

Except for one, all respondents agreed that it makes a difference where the advertisement is placed. Advertisements positioned at the beginning are tolerated by most respondents as it is expected and familiar that there will be advertising in this place, also from other channels such as TV or cinema. However, several respondents stated that they skip these advertisements as soon as possible as they are eager to watch the video.

Advertisements placed in the middle are considered as particularly annoying and disturbing by most respondents. At the same time, P04 and P09 acknowledged that they are most likely to watch mid-roll advertisements as they want to know how the video continues. These statements support the finding of Krishnan and Sitaraman (2013) that mid-roll advertisements have the highest completion rates. However, P08 explained that if the video has not caught sufficient interest, the appearance of a mid-roll advertisement can be a reason for her to leave the entire video. The most preferred form of all respondents are post-roll advertisements as these can either be skipped to continue with the next video or can be avoided by just putting for example the phone away or closing YouTube. This is further evidenced by Krishnan's and Sitaraman's (2013) finding that post-roll advertisements have the lowest completion rates.

As Krishnan and Sitaraman (2013) argued that advertisements placed in longer videos have higher completion rates than those placed in short videos, interviewees were also asked whether they mind advertisements less if the videos are longer than five minutes. This was partially confirmed as six respondents agreed that they mind the advertisements less in longer videos since they have to invest more time to complete the video anyway and that advertisements are expected in longer videos, comparable with TV. However, the remaining respondents stated that the video length does not make any difference. Instead, P06, P09 and P10 indicated that the 
advertisement's position has a more significant effect on their advertisement acceptance than the length of the video.

\section{Use of YouTube for Tourism Industry}

To investigate the role of YouTube for the tourism industry, participants were asked how they use YouTube in relation to travelling. Six respondents confirmed that they have already used YouTube to search for information before going on a trip. The searched information included the major sights, excursion tips, local specialities, experience reports of people who already travelled to the destination and directions. All six respondents concurred that YouTube offers extensive information and that they found everything they were looking for. Nevertheless, the majority of nine respondents stated that they have not used YouTube for information search yet. The main reason given was that there was no awareness that information such as an overview of the top sights is provided on YouTube.

P1 argued that she prefers text-based websites as it is easier to find immediately what is needed and that the search on YouTube is more complicated than on search engines such as Google. P05 added that looking for information on YouTube is quite time-consuming whereas a search initiated via Google is faster. Moreover, P07 stated that he perceives videos as too superficial and, thus, prefers text-based information. However, none of the respondents who do not use YouTube for information search has any other specific websites they prefer for information search. Their search processes start usually with a general search on Google. Except for P01, P05 and P07, the remaining respondents who do not use YouTube yet sympathised with the idea of using YouTube in the future. These findings confirm the importance of social media channels such as YouTube for information search within the tourism industry as previously identified by Xiang and Gretzel (2010). Moreover, the answers indicate a tremendous future potential for organisations within the tourism industry to provide users with specialised content regarding destinations via YouTube.

\section{Conclusion}

The exposure to the tourism advertisement resulted in successful brand and advertisement recall. However, in terms of the attitude towards the tourism advertised brand and purchase intention, no particularly positive effect could be identified. Although the advertisement recall was greater in the incongruent group, no significant observations could be made in regards to the differences between the two groups. This is mainly due to the fact that the perception of congruence is highly subjective and cannot be judged by third parties. However, it needs to be noticed that this analysis refers only to the immediate effects of the exposure to the advertisement. One of the major problems in assessing tourism advertising effectiveness is that the effects might occur delayed, for example, a purchase is 
made after weeks of exposure to the advertisement (Moriarty et al. 2014). Supportive to this notion is that several respondents acknowledged that through the constant repetition of the advertisement, the familiarity with the brand increases which might also increase the likelihood that a purchase via Trivago is made.

The interviews were used to analyse whether negative effects are related to the exposure to YouTube advertising within the tourism industry. No immediate negative effects were observed among the residual respondents. Instead of changing their attitude towards the brand, the majority of respondents kept a neutral opinion of the brand. Thus, no significant positive but also no negative effects of the exposure to YouTube advertising in regards to the attitude towards the brand could be identified.

However, it was stated by several respondents that the repetitive exposure to the same Trivago advertisement on YouTube and across other channels leads to feelings of annoyance and tedium. Additionally, several avoidance behaviours were described by respondents. With the appearance of an advertisement, participants often open, for example, another tab, check their phone or just look away to avoid the exposure to the advertisement. According to Smith (2012) and Truong and Simmons (2010), reasons for these reactions can be the overuse of advertisements and an overly high degree of intrusiveness. Thus, it can be concluded that the exposure to YouTube advertising per se does not have negative effects but the way it is executed can lead to negative reactions. Therefore, the degree of intrusiveness should be reduced to decrease avoidance behaviours and achieve more active advertisement processing. Investigating the factors influencing the effectiveness, it was identified that mid-roll advertisements are perceived as most annoying and disturbing. In order to decrease the degree of intrusiveness, advertisement types such as mid-roll advertisements should rather be avoided and instead, for example, pre-roll advertisements used. Additionally, varying tourism advertisements should be employed as the research showed that respondents are more likely to watch an advertisement if it is something interesting they have not seen before. This suggests also that advertisements used for television should not be used on YouTube to reduce the repetitive exposure to the same advertisements.

The research objective requires recommendations whether the use it was found that due to its high intrusiveness, YouTube advertising is a suitable channel to create tourism brand awareness and also to keep the brand in the customer's mind. However, the research has shown that in regards to tourism advertising objectives such as building brand preference or persuading consumers to purchase, YouTube is not the ideal channel. Findings confirmed that as the user has a specific objective when watching a video, there is no willingness to purchase when processing content on YouTube. Instead, Facebook was identified as a more suitable channel when it comes to persuading customers to buy. However, it was also noticed that the products the interviewees bought via Facebook were predominantly lowinvolvement products such as make-up, phone covers or books. Due to their higher cost, products related to travelling can be considered as high-involvement products as a higher financial risk is involved for the consumer (Leung et al. 2013). Thus, it can be assumed that impulse purchases on Facebook as described by the 
respondents, do not occur in regards to tourism-related products because of the higher involvement required. Therefore, it can be concluded that the effectiveness of YouTube advertising depends on an organisation's specific advertising objectives. It can also be questioned whether online advertising is in general suitable for the achievement of persuasive advertising objectives within the tourism industry due to the high involvement required when purchasing the products.

Furthermore, the research has revealed YouTube's significant potential for information search within the tourism industry. It is, therefore, recommended that touristic organisations such as Trivago make more use of the opportunity to provide branded content on YouTube by uploading videos containing, for example, tips for a destination's top accommodations and clearly visualise the logo of the brand within these videos. Especially for organisations with smaller advertising budgets, this would represent a suitable alternative to the costly advertising.

Previous studies did not assess the suitability of YouTube advertising for a specific industry. Due to the significance of social media for the tourism industry, the industry's high overall expenditures on advertising and YouTube's growing importance for the search of travel-related information, this study is the first which investigated the effectiveness of YouTube advertising in the context of the tourism industry.

As platforms such as Instagram and Snapchat are increasingly offering opportunities for online video advertising, this research should be replicated with a focus on these platforms. Conducting a cross-comparison with the findings of this research would enable tourism marketers to gain a more comprehensive picture of the strengths and opportunities of each platform and provide them with a better understanding on how to allocate budgets in order to maximise advertising effectiveness.

\section{References}

Ayeh JK, Au N, Law R (2013) "Do we believe in TripAdvisor?" Examining credibility perceptions and online travellers' attitude toward using user-generated content. Journal of Travel Research 52(4): 437-452.

Belanche D, Flavian C, Perez-Rueda A (2017) Understanding interactive online advertising: congruence and product involvement in highly and lowly arousing, skippable video ads. Journal of Interactive Marketing 37(Feb): 75-88.

Blattberg E (2015) The demographics of YouTube, in 5 charts. Retrieved from: http://digiday.com/media/demographics-youtube-5-charts/.

Broussard G (2000) How advertising frequency can work to build online advertising effectiveness. International Journal of Market Research 42(4): 439-457.

Calder BJ, Malthouse EC, Schaedel U (2009) An experimental study of the relationship between online engagement and advertising effectiveness. Journal of Interactive Marketing 23(4): 321-331.

Cameron S, Price D (2009) Business research methods: a practical approach. London: Chartered Institute of Personnel and Development. 
Chandon JL, Chtourou MS, Fortin DR (2003) Effects of configuration and exposure levels on responses to web advertisements. Journal of Advertising Research 43(2): $217-$ 229.

Chatterjee P (2001) Beyond CPMs and clickthroughs: consumer interaction with web advertising. Internet Marketing Research: Theory and Practice (Jun): 209-216.

Cox C, Burgess S, Sellitto C, Buultjens J (2009) The role of user-generated content in tourists' travel planning behavior. Journal of Hospitality Marketing \& Management 18(8): 743-764.

Crowel H, Gribben H, Loo J (2014) Travel content takes off on YouTube. Think with Google. Retrieved from: https://www.thinkwithgoogle.com/consumer-insights/travelcontent-takes-off-on-youtube/.

Dehghani M, Niaki MK, Ramezani I, Sali R (2016) Evaluating the influence of YouTube advertising for attraction of young customers. Computers in Human Behavior 59(Jun): 165-172.

Drèze X, Hussherr FX (2003) Internet advertising: is anybody watching? Journal of interactive marketing 17(4): 8-23.

DRV - Deutscher Reiseverband (2017) Fakten und Zahlen zum Reisemarkt. (Facts and figures about the travel market). Retrieved from: https://www.drv.de/fachthemen/ statistik-und-marktforschung/fak ten-und-zahlen-zum-reisemarkt.html. [Accessed 8 July 2017].

eMarketer (2016a). Digital video advertising continues to expand. Retrieved from: https://www.emarketer.com/Article/Digital-Video-Advertising-Continues-Expa $\mathrm{nd} / 1013722$.

Faith C (2014). The top industries spending the most on AdWords and why. Smartsites Blog. Retrieved from: http://www.smartsites.com/blog/top-industries-spendingadwords/.

Fotis J, Buhalis D, Rossides N (2012) Social media use and impact during the holiday travel planning process. In M Fuchs, F Ricci, L Cantoni (Eds), 13-24. Information and Communication Technologies in Tourism 2012. Vienna: Springer-Verlag.

Huang J, Su S, Zhou L, Liu X (2013) Attitude toward the viral ad: expanding traditional advertising models to interactive advertising. Journal of Interactive Marketing 27(1): $36-46$.

Hudson S, Thal K (2013) The impact of social media on the consumer decision process: implications for tourism marketing. Journal of Travel \& Tourism Marketing 30(1-2): 156-160.

Hwang J, Yoon YS, Park NH (2011) Structural effects of cognitive and affective responses to web advertisements, website and brand attitudes, and purchase intentions: the case of casual-dining restaurants. International Journal of Hospitality Management 30(4): 897-907.

Ibrahim M (2013). Digital marketing is "invasive and annoying", study claims. Campaignlive. Retrieved from: http://www.campaignlive.co.uk/article/digitalmarketing-invasive-annoying-study-claims/1185778.

Jhonsa E (2016) Trivago's eye-popping advertising spend might be responsible for its uninspiring IPO. Retrieved from: https://www.thestreet.com/story/ 13929348/2/trivago-s-eye-popping-advertising-spend-might-be-responsible-for-itsuninspiring-ipo.html.

Kotler P, Armstrong G (2016) Principles of marketing. $16^{\text {th }}$ Edition. Harlow: Pearson Education Limited. 
Krishnan SS, Sitaraman RK (2013) Understanding the effectiveness of video ads: a measurement study. In Proceedings of the 2013 conference on internet measurement, 149-162. Retrieved from: http://dl.acm.org/ citation.cfm?id=2504748. [Accessed 10 February 2017].

Lavrakas PJ, Mane S, Laszlo J (2010) Does anyone really know if online ad campaigns are working? Journal of Advertising Research 50(4): 354-373.

Lee J, Lee H (2012) Canonical correlation analysis of online video advertising viewing motivations and access characteristics. New Media \& Society 14(8): 1358-1374.

LePage E (2016). All the social media advertising stats you need to know. Hootsuite Blog. Retrieved from: https://blog.hootsuite.com/social-media-advertising-stats/.

Leung D, Law R, Van Hoof H, Buhalis D (2013) Social media in tourism and hospitality: a literature review. Journal of Travel \& Tourism Marketing 30(1-2): pp. 3-22.

Li H, Lo HY (2015) Do you recognize its brand? The effectiveness of online in-stream video advertisements. Journal of Advertising 44(3): 208-218.

Manap KA, Adzharudin NA (2013) The role of user generated content (UGC) in social media for tourism sector. In The 2013 WEI International Academic Conference Proceedings, 52-58. Retrieved from: https://pdfs.semanticscholar.org/8b03/c9 ca4d8238938629d9afc0e1245067f118bc.pdf. [Accessed 3 June 2017].

Martín-Santana JD, Beerli-Palacio A (2012) The effectiveness of web ads: rectangle vs contextual banners. Online Information Review 36(3): 420-441.

Metha A (1994) How advertising response modelling (ARM) can increase ad effectiveness. Journal of Advertising Research 34(3): 62-62.

Miller M (2011) YouTube for business: online video marketing for any business. $2^{\text {nd }}$ Edition. Indianapolis, Ind.: Que.

Moriarty S, Mitchell ND, Wells WD, Crawford R, Brennan L, Spence-Stone R (2014) Advertising: principles and practice. Australia: Pearson.

Nielsen (2016). The latest YouTube stats on audience demographics: who's turning in. Retrieved from: https://www.thinkwithgoogle.com/data-collectio ns/youtube-viewerbehavior-online-video-audience/. [Accessed 20 February 2017].

Pavlou P, Stewart D (2000) Measuring the effects and effectiveness of interactive advertising. Journal of Interactive Advertising 1(1): 61-77.

Pratt S, McCabe S, Cortes-Jimenez I, Blake A (2010) Measuring the effectiveness of destination marketing campaigns: Comparative analysis of conversion studies. Journal of Travel Research 49(2): 179-190.

Quinlan C (2011) Business research methods. Andover: Cengage Learning.

Reino D, Hay B (2016) The use of YouTube as a tourism marketing tool. Retrieved from: http://scholarworks.umass.edu/ttra/2011/Visual/69/. [Accessed 4 June 2017].

Robinson H, Wysocka A, Hand C (2007) Internet advertising effectiveness: the effect of design on click-through rates for banner ads. International Journal of Advertising 4(Jun): 527-541.

Rohrs J (2014) Audience marketing in the age of subscribers, fans \& followers. Hoboken: Wiley.

Rosenkrans G (2009) The creativeness and effectiveness of online interactive rich media advertising. Journal of Interactive Advertising 9(2): 18-31.

Rowley J (2012) Conducting research interviews. Management Research Review 35 (3-4): 260-271.

Shani A, Chen PJ, Wang Y, Hua N (2010) Testing the impact of a promotional video on destination image change: application of China as a tourism destination. International Journal of Tourism Research 12(2): 116-133. 
Shields M (2016) YouTube's quest for TV advertising dollars. The Wall Street Journal. Retrieved from: https://www.wsj.com/articles/youtubes-quest-for-tv-advertisingdollars-1461343177.

Smith K (2012) Longitudinal study of digital marketing strategies targeting Millennials. Journal of Consumer Marketing 29(2): 86-92.

Solomon MR (2013) Consumer behavior: buying, having and being. $10^{\text {th }}$ Edition. Upper Saddle River New York: Pearson Prentice Hall.

Statista (2016) Leading countries based on number of monthly active YouTube users as of $I^{\text {st }}$ quarter 2016. Retrieved from https://www.statista.com/statis tics/280685/numberof-monthly-unique-youtube-users/. [Accessed 10 February 2017].

Wordstream (2011) What industries contributed the most to Google's earnings? Retrieved from http://www.wordstream.com/articles/google-earnings. [Accessed 14 May 2017].

Xiang Z, Gretzel U (2010) Role of social media in online travel information search. Tourism management 31(2): 179-188.

YouTube (2012) YouTube in-stream ads. Retrieved from: https://static.goo gleusercontent.com/media/www.youtube.com/en//yt/advertise/medias/pdfs/instreamonesheeter-en.pdf. [Accessed 14 May 14 2017].

YouTube (2017) YouTube for press. Retrieved from https://www.youtu be.com/intl/enGB/yt/about/press/. [Accessed 5 August 2017].

Zeng B, Gerritsen R (2014) What do we know about social media in tourism? A review. Tourism Management Perspectives 10(Apr): 27-36. 